\title{
ANALISE MULTITEMPORAL DO USO E OCUPAÇÃO DO SOLO DA BACIA HIDROGRÁFICA DO ALTO GUARIROBA.
}

\author{
Luan Silva do Nascimento ${ }^{1}$
}

Mauro Henrique Soares da Silva ${ }^{2}$

\begin{abstract}
RESUMO
Através da análise multitemporal do uso e ocupação do solo, a presente pesquisa tem por finalidade compreender se os objetivos traçados com a criação da Área de Proteção Ambiental (APA) do Guariroba estão sendo cumpridos e, desta maneira, beneficiando a população residente nesta área próximo a região urbana de Campo Grande - MS. A APA possui grande importância, pois é o principal sistema produtor de água bruta para abastecimento público da cidade. Para realização da pesquisa foi utilizado o software Spring para processar as imagens de satélite, realizando os procedimentos de Contraste (realce), Composição Colorida, Recorte, Segmentação, Classificação Supervisionada e pós classificação de Imagens dos Satélites Landsat 5 e Landsat 8. De modo complementar ainda foram usados softwares como Google Earth e Excel. Além dos recursos computacionais, ocorreram visitas a campo para verificar a verdade real do terreno. Os resultados mostraram que nos $82,3 \mathrm{~km}^{2}$ da área total da bacia hidrográfica do Alto Guariroba, alvo de estudos da análise multitemporal, as mudanças da paisagem não foram significativas quantitativamente, no entanto, qualitativamente verificou-se um aumento da pastagem e das áreas com solo exposto, seguido da diminuição da vegetação Nativa, sendo esses dados suficientes para concluir a não eficácia da implementação da APA como estratégia para a conservação dos recursos naturais.
\end{abstract}

PALAVRAS-CHAVE: Análise Multitemporal, Uso e Ocupação do Solo, Área de Proteção Ambiental.

\section{MULTITEMPORAL ANAYSIS OF THE USE AND OCCUPATION OF THE SOIL OF ALTO GUARIROBA WATERSHED}

ABSTRACT

\footnotetext{
${ }^{1}$ Acadêmico do curso de Agronomia, Universidade ANHANGUERA UNIDERP, bolsista Voluntário de Iniciação Científica. luan.nascimento@uniderp.edu.br.

${ }^{2}$ Doutor em Geografia, Universidade ANHANGUERA UNIDERP, Professor Titular. mauro.soares@uniderp.edu.br.
} 
Through the multitemporal analysis of the use and occupation of the soil, this research objectives to understand if the goals made with the creation of the Guariroba Environmental Protection Area (APA) are been achieved and, so, benefiting the population living in this area next to the urban region of Campo Grande-MS. APA has great importance, because it is the mainly productive system of raw water to the public supply of the city. The Spring software was used to this research to process the images of the satellite, achieving the contrast procedure(enhance), Coloring composition, cutting, segmentation, supervised classification and post classification of the images from the satellites LANDSAT 5 and LANDSAT 8. To complete this work, it was also used software like Google, Earth and Excel. In addition to computer resources, camping visit also occurred to check the real truth of the land. The results showed that in the 82, 3 square $\mathrm{km}$ of the total area of Alto Guariroba watershed, target of the multitemporal analysis, the changes in the landscape were not quantity significant, however, in quality an increase in the pasture land and areas with exposed soil followed by the decrease of native vegetation, being these data enough to the implementation of APA as a strategy to the conservation of natural resources.

\title{
ANÁLISIS MULTITEMMPRAL DEL USO Y OCUPACIÓN DEL SUELO DE LA CUENCA HIDROGRÁFICA DEL ALTO GURARIROBA
}

\begin{abstract}
RESUMEN
Por medio del análisis multitemporal del uso y ocupación del suelo, esta investigación tuvo como finalidad comprender sí los objetivos trazados con la creación del Área de Protección Ambiental (APA) Guariroba están siendo cumplidos satisfactoriamente y consecuentemente beneficiando a población local, residente de esta área próxima a la región urbana de Campo Grande-MS Esta APA es de gran importancia pues constituye el principal sistema productor de agua salubre para el abastecimiento público de la ciudad. Con ayuda del software Spring se procesaron imágenes de satélite aplicando procedimientos de contraste (realce), composición a color, recorte, segmentación, clasificación supervisada y pos-clasificación de imágenes de los satélites Landsat 5 y Landsat 8. Para complementar, también fueron usados software como Google Earth y Exel. Además de los recursos computacionales, fueron efectuadas visitas a campo para verificar la veracidad del terreno de la APA. Los resultados obtenidos mostraron que en los $82,3 \mathrm{~km}^{2}$ del área de la cuenca hidrográfica del Alto Guariroba, principal foco de los análisis multitemporales, los cambios paisajísticos no fueron significativos cuantitativamente, sin embargo, cualitativamente fue posible evidenciar un aumento de pastizales y de áreas con el suelo expuesto, además de la disminución de la vegetación nativa. Estos datos fueron suficientes para concluir la ineficacia de la implementación de la APA Guariroba como estrategia para la conservación de los recursos naturales.
\end{abstract}

PALABRAS CLAVE: Análisis Multitemporal, Uso y ocupación del suelo, Área de Protección Ambiental.

\section{Introdução}

Instituída pelo Poder Público Municipal através do Decreto $N^{\circ} 7.183$, de 21 de setembro de 1995, a APA do Guariroba teve sua criação vinculada à necessidade de recuperação e conservação do principal sistema produtor de água bruta para 
abastecimento público de Campo Grande. A APA do Guariroba está situada integralmente no município de Campo Grande, tendo como referência a localização da represa (Reservatório Guariroba), acessada pela BR-262, verifica-se uma distância de aproximadamente 35 quilômetros em relação ao Centro da cidade de Campo Grande. (PREFEITURA MUNICIPAL DE CAMPO GRANDE, 2008).

As Áreas de Proteção Ambiental (APA) exercem um papel importante tanto para sociedade como para o ambiente, onde a ideia principal é que ocorra um uso adequado dos recursos naturais. A base legal para criação das Áreas de Proteção Ambiental (APA) remonta o início da década de 1980, quando da publicação da Lei Federal N..$^{\circ}$ 6.902, de 27 de abril de 1981, que no seu artigo $8^{\circ}$, estabeleceu que "havendo relevante interesse público, os poderes executivos Federal, Estadual ou Municipal poderão declarar determinadas áreas dos seus territórios de interesse para a proteção ambiental, a fim de assegurar o bem-estar das populações humanas, a proteção, a recuperação e a conservação dos recursos naturais".

A bacia hidrográfica compreende a área geográfica que drena suas águas para um determinado recurso hídrico. A qualidade da água de um manancial depende diretamente do uso e atividades desenvolvidas em toda a bacia hidrográfica. (MOTA, 1995).

A APA possui vários recursos naturais, sendo esses recursos de suma importância para região. Entre os principais se encontram a água, o solo, a fauna e a flora. Reconhecidamente, a pecuária é a principal atividade econômica desenvolvida na APA. De modo geral, tanto as pequenas, como as médias e grandes propriedades, têm na pecuária extensiva o suporte para a manutenção da viabilidade econômica do estabelecimento. (PREFEITURA MUNICIPAL DE CAMPO GRANDE, 2008).

A necessidade de água é universal, com isso a água se torna um dos recursos naturais mais indispensáveis para a sociedade e para o planeta. Devido a sua distribuição em todo planeta e sua aparente inesgotabilidade têm levado a humanidade a tratar esse importante recurso natural sem conservação (BERTONI e NETO, 1990), esse é um problema que preocupa, pois em determinadas regiões a 
escassez de água é evidente, e já se sabe que é necessário que aconteça um trabalho de conservação da água e de outros recursos naturais.

O solo é de relevante importância, porque grande parte dos nossos alimentos, direta ou indiretamente, provém de campos de cultivo e de pastagens (LEPSCH, 2010). O solo é um recurso básico que suporta toda a cobertura vegetal da terra, sem a qual os seres vivos não poderiam existir. Nessa cobertura incluem-se não só as culturas como, também, todos os tipos de árvores, gramíneas, raízes e herbáceas que podem ser utilizadas pelo homem (BERTONI e NETO, 1990).

Deste modo, a APA do guariroba foi criada para preservar os recursos ali presentes de modo a melhorar cada vez mais as condições do ambiente e que a agricultura ali presente seja explorada de forma sustentável, que respeite o meio ambiente e garanta a produção e uma boa qualidade de vida para a população.

Sendo assim, a pesquisa realizada buscou compreender se os objetivos traçados com a criação da APA do Guariroba, estão sendo cumpridos e desta maneira beneficiando a sociedade, sobretudo a população local da Área de Proteção Ambiental.

Pesquisas voltadas para essas áreas são de extrema importância, pois podem mostrar além dos erros, as alternativas para melhoria, além de observar se a Área de Proteção Ambiental está cumprindo com seu objetivo que é disciplinar o processo de ocupação, proteger a diversidade biológica e assegurar o uso sustentável dos recursos naturais (CABRAL E SOUZA, 2005).

Em suma, o objetivo geral da referida pesquisa foi o de avaliar as mudanças da paisagem da Área de Preservação Ambiental da Bacia Hidrográfica do Guariroba por meio da análise do uso e ocupação do solo, utilizando ferramentas e tecnologias voltadas para gerar dados que irão mostrar se a APA está cumprindo o seu objetivo principal de preservação dos recursos naturais da área. 


\section{Procedimentos Metodológicos}

Para o desenvolvimento destas analises foram utilizados duas imagens de satélite: a primeira L5TM Orbita 225 Ponto 74 datada em 18/05/1994 a segunda é LC8 Orbita 225 Ponto 74 datada em 09/05/2014 as quais foram geoprocessadas em ambiente SIG.

As imagens de satélites selecionadas foram obtidas de dois sites, que disponibilizam essas imagens gratuitamente para fins de pesquisas. As imagens de 1994 foram adquiridas no site do Instituto Nacional de Pesquisas Espaciais (INPE), a imagem de 2014 foi obtida no site da U. S. Geology Survey (USGS).

Os sensores TM e ETM do satélite LANDSAT 5 possuem sete bandas, sendo que cada banda representa uma faixa do espectro eletromagnético captada pelo satélite. O satélite LANDSAT 5 revisita (observa) a mesma área a cada 16 dias. Foram selecionadas as bandas 3,4 e 5 deste satélite.

As bandas possuem características e aplicações especificas, a banda número três foca a vegetação verde, densa e uniforme, apresenta grande absorção, ficando escura, permitindo bom contraste entre as áreas sem cobertura vegetal (ex.: solo exposto, estradas e áreas urbanas), e os diferentes tipos de vegetação (ex.: campo, cerrado e florestas).

$\mathrm{Na}$ banda quatro os corpos de água absorvem muita energia e ficam escuros, permitindo o mapeamento da rede de drenagem e delineamento de corpos de água. $A$ vegetação verde, densa e uniforme, reflete muita energia nesta banda, aparecendo bem claro nas imagens. Apresenta sensibilidade à rugosidade da copa das florestas (dossel florestal). Serve para separar e mapear áreas ocupadas com pinus e eucalipto. Permite a identificação de áreas agrícolas.

A banda cinco apresenta sensibilidade ao teor de umidade das plantas, servindo para observar estresse na vegetação, causado por desequilíbrio hídrico. Esta banda sofre perturbações em caso de ocorrer excesso de chuva antes da obtenção da cena pelo satélite.

O satélite LANDSAT 8 entrou em operação em 2013, possui uma quantidade de bandas maior do que as encontradas no LANDSAT 5, no LC8 (LANDSAT 8) 
as imagens consistem em nove bandas espectrais com uma resolução espacial de 30 metros para as bandas 1-7. Neste caso as bandas escolhidas foram as de número 4, 5 e 6, pois possuem resultados similares as bandas numero 3, 4 e 5 do satélite LANDSAT 5.

O software que foi utilizado é o Spring que é um SIG (Sistema de Informações Geográficas) com funções de processamento de imagens, análise espacial, modelagem numérica de terreno e consulta a bancos de dados espaciais.

Por meio do software Spring foram aplicados os seguintes procedimentos nas imagens: Contraste (realce), Composição Colorida, Recorte, Segmentação e Classificação Supervisionada.

O primeiro procedimento foi à aplicação de contraste (realce) nas imagens. O Contraste (realce) é uma técnica simples e eficiente para destacar objetos e feições. A finalidade das técnicas de realce é melhorar a qualidade visual das imagens e facilitar o trabalho de interpretação (CUNHA, 2009).

As imagens obtidas por sensores eletrônicos são originalmente processadas em preto e branco, mas dessas imagens é possível gerar composições coloridas associando duas ou três imagens às cores primárias azul, verde e vermelho. Nas imagens de satélites foram utilizadas composições coloridas com as cores azul (blue), verde (green) e vermelho (red) nas bandas 3, 4 e 5 LANDSAT 5 e bandas 4, 5 e 6 LANDSAT 8 respectivamente.

A etapa seguinte foi à utilização da técnica do recorte, o principal objetivo do recorte de imagens é facilitar o trabalho do analista, devido às imagens de satélite LANDSAT representar no solo 185 x 185 km, por ser uma imagem de vasta extensão pode prejudicar o desempenho do trabalho do analista se a área estudada for pequena dentro da imagem, devido a isto aplica-se a técnica do recorte para um melhor entendimento do analista, e com isso possibilitará um melhor desempenho do seu trabalho.

Para isso optou-se pelo recorte espacial da Bacia hidrográfica do Alto Guariroba, como alvo de estudo (Figura 1), onde foi analisado a evolução do processo de uso e ocupação do solo nos últimos 20 anos, por meio de analise 
multitemporal de imagens de satélite, de modo a identificar possíveis problemas, antes e depois do período de criação da APA.

Figura 1: Localização da Área de Estudo

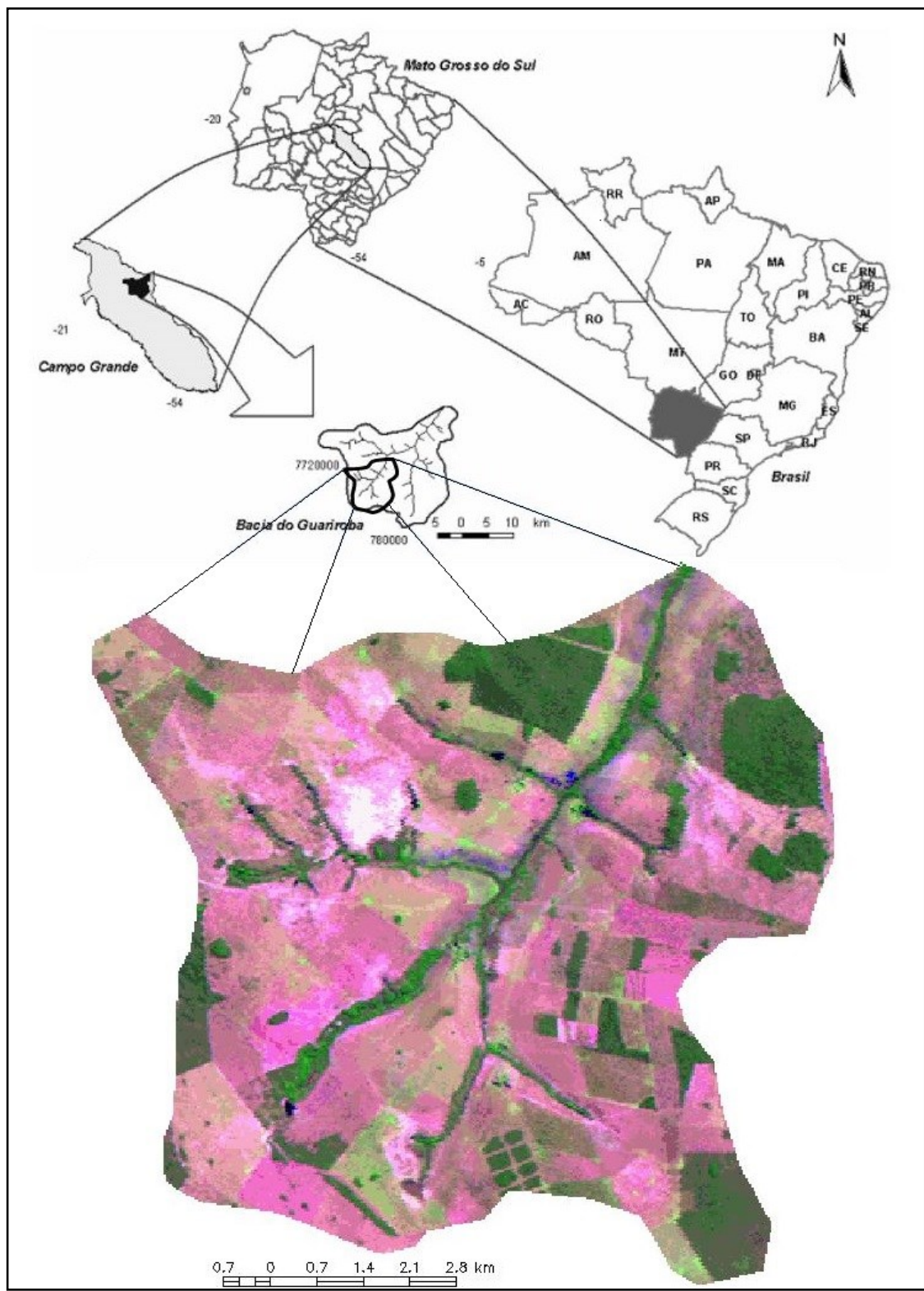

Fonte: Yamaciro (2007) e imagem LANDSAT 5 orbita e ponto 225/74 de 18/05/2004

O próximo processo foi à segmentação de imagens que é um procedimento computacional aplicado antes de um algoritmo de classificação automática. A segmentação permitiu dividir a imagem em regiões espectralmente homogêneas 
Volume 10, Número 2, 2014

Bacias Hidrográficas, Planejamento e Gestão dos Recursos Hídricos

(FLORENZANO, 2011). Nelas foi possível definir as amostras (áreas de treinamento) para aplicação de um algoritmo de classificação supervisionada.

Antes da realização da classificação e pós classificação foi elaborada a chave de Interpretação (Figura 2), identificando assim as classes de uso do solo que foram adotadas para o mapeamento da área, sendo essas: pastagem, solo nu, vegetação nativa, Plantação e Corpo hídrico. Nessa fase o Google Earth foi também uma ferramenta de auxílio utilizada para a leitura das imagens e identificação das classes, além de visitas ao local de estudo, na região da APA do Guariroba, mais especificamente na Bacia hidrográfica do Alto Guariroba, no período de 24 a 25 do mês de junho, analisando 16 pontos de observação e a partir daí foi possível observar melhor a área e tirar as dúvidas que haviam surgido, completando assim a verdade real do terreno.

Figura 2: Chave de Interpretação

\begin{tabular}{|c|c|c|c|c|}
\hline CLASSE & $\begin{array}{l}\text { IMAGEM } \\
\text { IANDSAT }\end{array}$ & $\begin{array}{c}\text { IMAGEM } \\
\text { GOOGLE EARTH }\end{array}$ & $\begin{array}{l}\text { COORDENADAS } \\
\text { GEOGRÁFICAS }\end{array}$ & FOTOS CAMPO \\
\hline Pastagem & & & $\begin{array}{l}\text { Lat: }-203936.98 \mathrm{~S} \\
\text { Long: }-542331.48 \mathrm{~W}\end{array}$ & \\
\hline Vegetação Nativa & & & $\begin{array}{c}\text { Lat: }-203553.66 \mathrm{~S} \\
\text { Long: }-542152.35 \mathrm{~W}\end{array}$ & \\
\hline Solo Nu & & & $\begin{array}{l}\text { Lat: }-203715.47 \mathrm{~S} \\
\text { Long: }-542042.75 \mathrm{~W}\end{array}$ & \\
\hline Corpo Hídrico & & & $\begin{array}{l}\text { Lat: - } 203721.73 \mathrm{~S} \\
\text { Long: }-542058.17 \mathrm{~W}\end{array}$ & \\
\hline Plantação & & & $\begin{array}{l}\text { Lat: }-203803.05 \mathrm{~S} \\
\text { Long: }-542108.14 \mathrm{~W}\end{array}$ & E \\
\hline
\end{tabular}


Em relação à classe denominada plantação, dentro da Bacia hidrográfica do Alto Guariroba, apesar da dificuldade de visualização pela imagem de satélite, constatou-se com a visita apenas uma pequena área de plantio dedicado a Silvicultura, e devido a isso essa classe foi mantida no mapeamento.

Com um melhor conhecimento sobre a área de estudo, a etapa seguinte da pesquisa foi à realização da classificação. A classificação de imagens digitais visa o reconhecimento automático de objetos, em função de determinado critério de decisão, agrupando em classes os objetos que apresentam similaridade em suas respostas espectrais. O resultado de uma classificação digital de imagens, portanto, é um mapa temático, no qual cada pixel ou grupo de pixels (quando a imagem é segmentada) da imagem foi classificado em uma das várias classes (ou temas) definidas. A técnica que foi utilizada na pesquisa é a classificação supervisionada onde as classes são definidas a priori pelo analista. (FLORENZANO, 2011).

Após a classificação foi necessário realizar um processo denominado de pósclassificação que tem por objetivo corrigir os erros resultantes da classificação automática, neste caso foi utilizado à edição matricial, que é um recurso computacional disponível no software Spring.

\section{Resultados e Discussões}

O mapa de uso do solo da Bacia do Alto Guariroba em 1994, possibilitou identificar a área em $\mathrm{km}^{2}$ de cada classe que foi determinada no trabalho. Assim dos $82,3 \mathrm{~km}^{2}$ da área de estudo, constatou-se que em 1994 a área possuía $54,2 \mathrm{~km}^{2}$ de pastagens, 2,68 km² de Solo $\mathrm{Nu}, 23,1 \mathrm{~km}^{2}$ de Vegetação Nativa, $0,23 \mathrm{~km}^{2}$ de área plantada e $2 \mathrm{~km}^{2}$ de Corpo Hídrico (Figura 3 ).

O produto final da imagem de satélite de 2014 (Figura 4), gerou dados em km² em relação às classes que foram determinadas, possibilitando uma analise dos dados em relação ao uso e ocupação do solo na Bacia hidrográfica do Alto Guariroba depois da sua criação. Os resultados de cada classe em $\mathrm{km}^{2}$ foram: Pastagem - 58,6 km², Solo Nú - 3,39 km², Vegetação Nativa $-19,1 \mathrm{~km}^{2}$, Plantação $-0,23 \mathrm{~km}^{2}$, Corpo Hídrico $-0,86 \mathrm{~km}^{2}$ e Área total $-82,3 \mathrm{~km}^{2}$. 
Figura 3: Uso e Ocupação do solo da Bacia Hidrográfica do Alto Guariroba - 1994

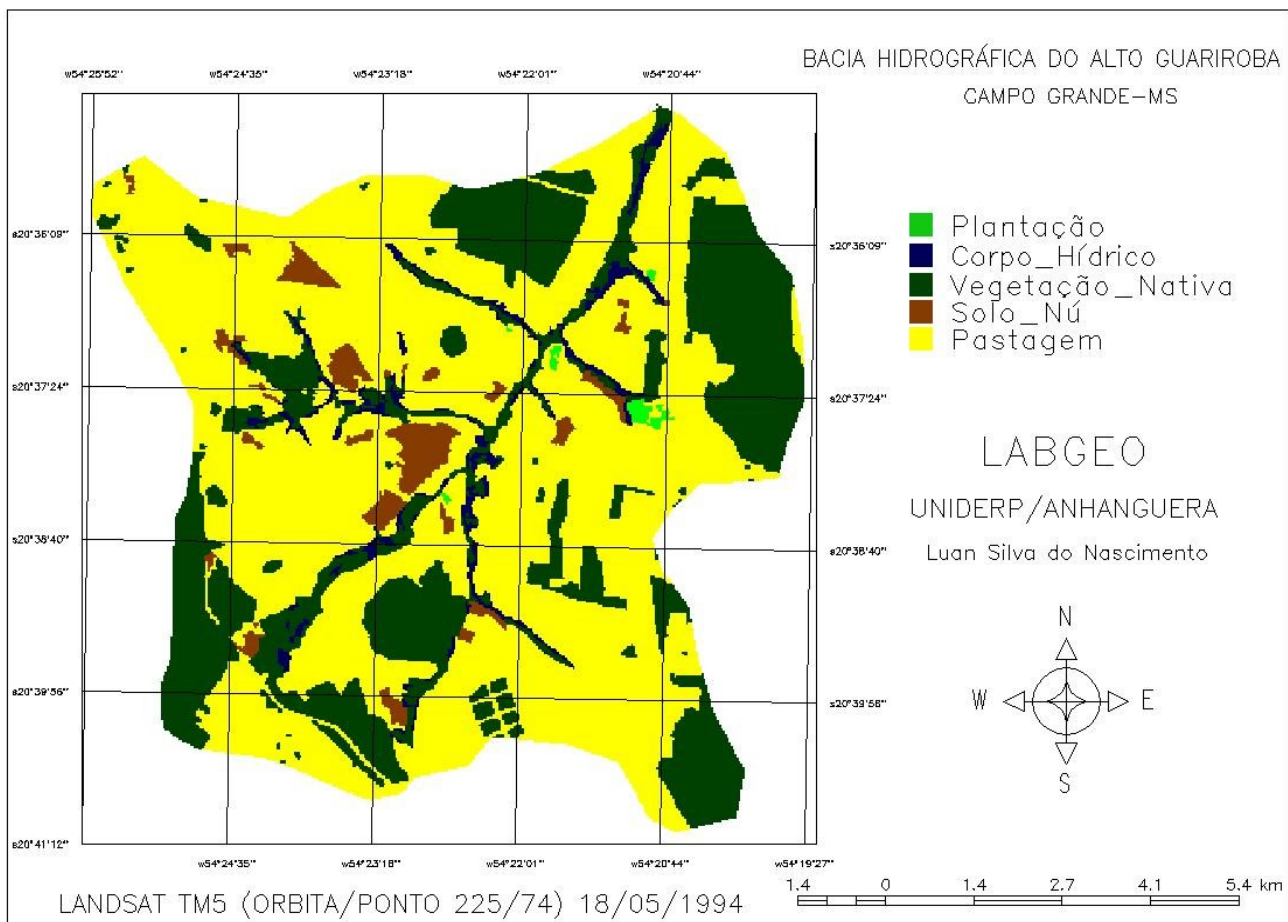

Figura 4: Uso e Ocupação do Solo da Bacia Hidrográfica do Alto Guariroba - 2014

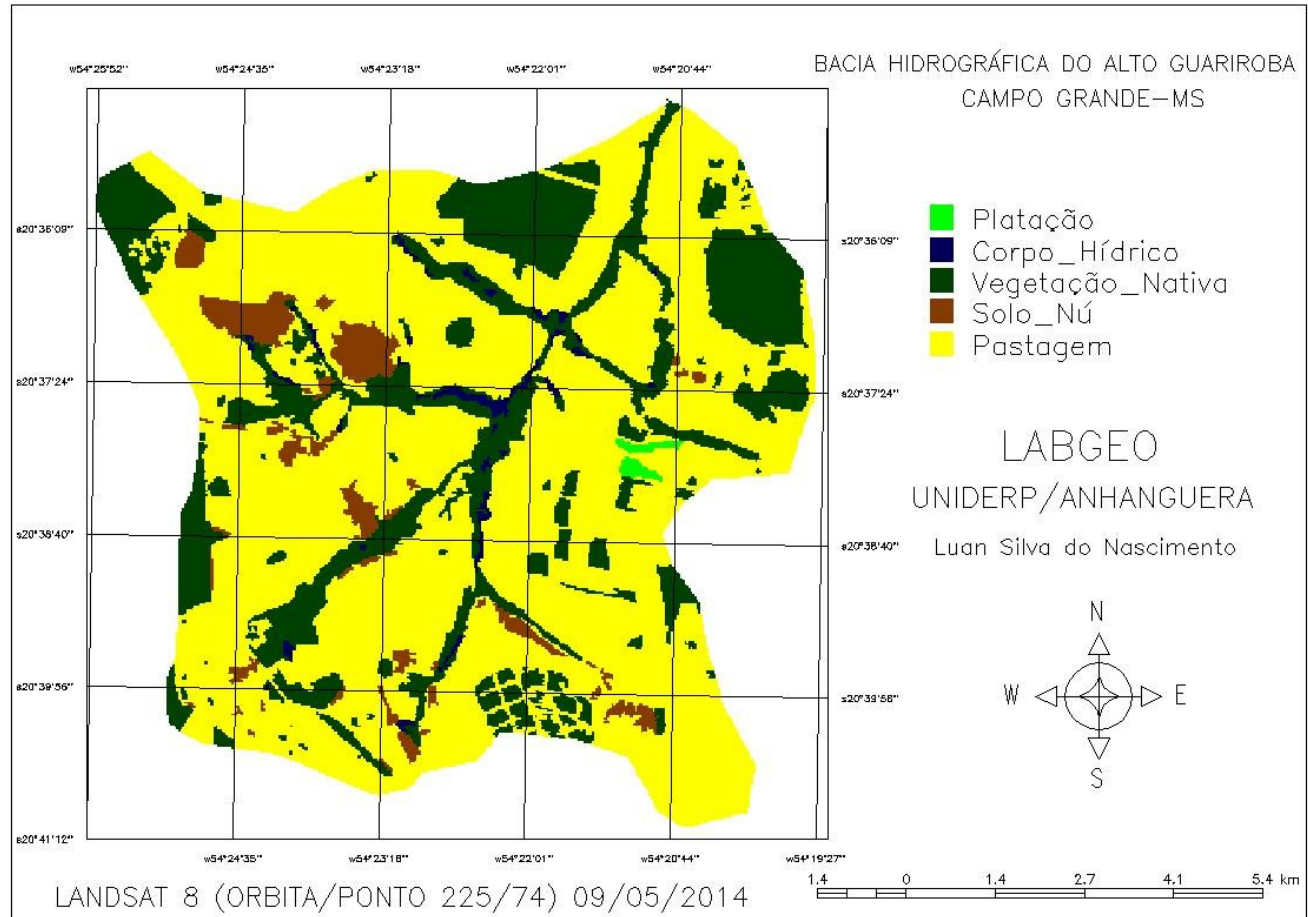

X Fórum Ambiental da Alta Paulista, v. 10, n. 2, 2014, pp. 525-538 
A evolução das classes de uso e ocupação do solo na área da bacia hidrográfica do Alto Guariroba nos últimos 20 anos revela que as mudanças na paisagem sugerem um significativo aumento das áreas de Pastagem e Solo $\mathrm{Nu}$ em detrimento da Vegetação Nativa, seguido ainda de uma variação inexpressiva das áreas plantadas, com redução da presença de água da área (Figura 5).

A pastagem teve um aumento de sua área cultivada em 2014 de $4,4 \mathrm{~km}^{2}$ que representa um acréscimo de aproximadamente $5 \%$ em relação à de 1994, ressalta-se que a pecuária é a pratica que gera o potencial econômico da região, devido a isso é a principal atividade na APA.

Com o passar dos 20 anos também ocorreu um aumento de $0,71 \mathrm{~km}^{2}$ (aproximadamente 1\%) do solo nu observado na área. Verifica-se que a APA possui solos muito danificados por um manejo inadequado.

Figura 5: Gráfico

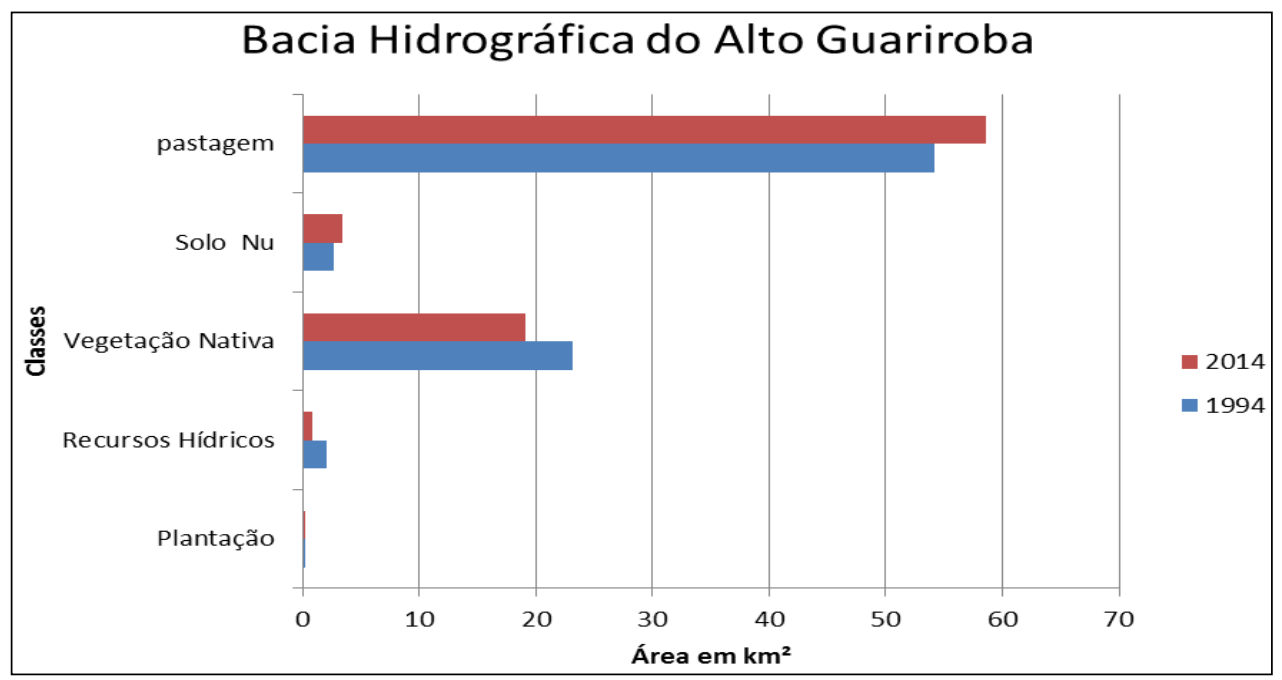

A vegetação nativa da área diminuiu $4 \mathrm{~km}^{2}$ (aproximadamente $5 \%$ ) em relação ao ano de 1994, sendo que isso pode se tornar um problema ainda maior para área devido à importância que a vegetação nativa tem para o ambiente de modo geral, podendo trazer consequências para os demais recursos naturais presentes na APA. 
Verifica-se que a cobertura vegetal tem papel fundamental para proteção do solo na área, pois segundo Mafra (2005) a erosão do solo é mais efetiva onde a água de precipitação não pode ser infiltrada. A água realiza uma trajetória relativamente rápida e é capaz de carrear materiais do solo por meio da força hidráulica de seu fluxo.

Lepsch (2010) afirma que um solo em harmonia com o ambiente é considerado sadio, ao passo que, um desajuste, está degradado e assim influencia negativamente o ambiente. Quando desprovido de sua vegetação natural, o solo fica exposto a uma série de fatores que tendem a depauperá-lo numa velocidade que varia com as características, o tipo de clima e os aspectos da topografia.

O corpo hídrico também teve redução em sua área de 1994 para o ano de 2014, nas imagens de 1994 essa classe aparecia de forma mais evidente na coloração dos pixels, já na imagem de 2014 essa coloração é de difícil visualização, mostrando de forma clara que essa classe teria diminuído $1,14 \mathrm{~km}^{2}$ que representa aproximadamente $2 \%$ em relação aos últimos 20 anos.

A classe plantação presente na APA não teve grande alteração em relação aos anos mencionados, pois esta prática não é muito utilizada na área de estudo, pois perde muito espaço para pecuária extensiva, no entanto as atividades de campo auxiliaram a identificar a prática do cultivo de Acacia Mangium (Figura 6), como exclusividade agrícola da área. 
Figura 6: Plantação (Acacia Mangium)

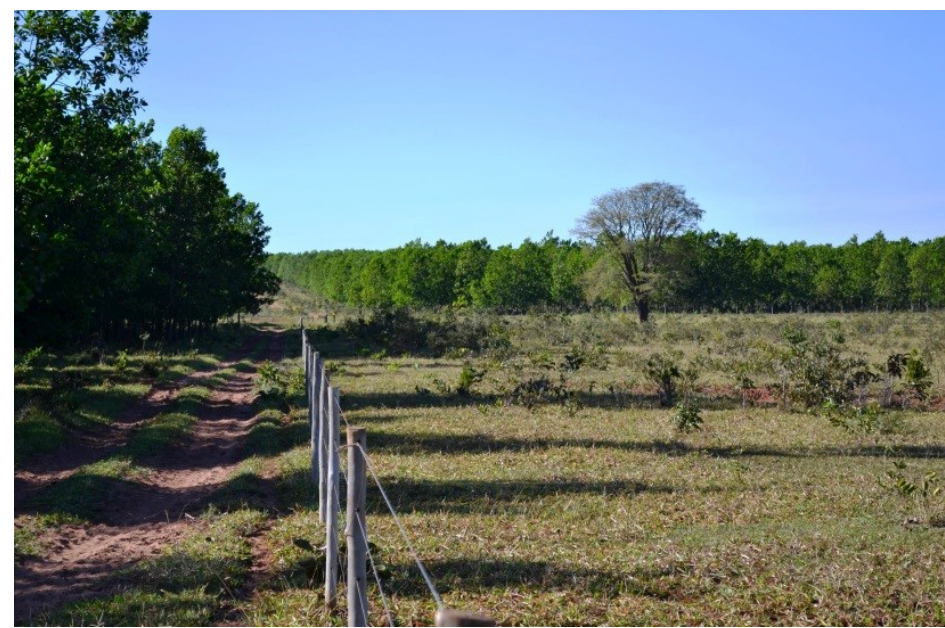

Fonte: Luan Nascimento Silva (2014).

A acácia é uma espécie nativa da parte noroeste da Austrália, de Papua NovaGuiné e do oeste da Indonésia, com potencial para cultivo nas zonas baixas e úmidas, cuja madeira apresenta usos variados, entre eles a construção civil e de móveis (SMIDERLE, 2005).

\section{CONCLUSÃO}

O uso de imagens LANDSAT na pesquisa foi fundamental, pois essas imagens foram processadas no software Spring onde foi feito um mapeamento da área e isso gerou dados quantitativos capazes de auxiliar na análise multitemporal do uso e ocupação do solo da bacia do Alto Guariroba.

Usando como estratégia metodológica o recorte da bacia hidrográfica do Alto Guariroba e o mapeamento da mesma, os resultados mostraram um aumento significativo da superfície recoberta por pastagens artificiais em detrimento da diminuição da cobertura vegetal de florestas nativas, sendo o fator mais impactante na mudança identificada na paisagem o aumento das áreas de solo exposto. Assim, estas condições evidenciam um manejo inadequado, sendo que esses fatores podem afetar de forma negativa a sociedade, sobretudo a população local da Área de Proteção Ambiental. 
Conclui-se que a Área de Proteção Ambiental do Guariroba não cumpri totalmente com suas funções, pois recursos naturais de extrema importância para o ambiente da bacia hidrográfica, como a vegetação nativa, estão diminuindo em relação a área que ocupavam antes da criação da APA do Guariroba, podendo ocasionar vários impactos diretos ao meio ambiente.

\section{REFERÊNCIAS}

MOTA, S. O Planejamento Territorial e a Conservação dos Recursos Hídricos. Preservação e Conservação de Recursos Hídricos. $2^{\circ}$ ed.; Rio de Janeiro, ABES, 1995. p. 107-116.

FLORENZANO, T. G. Processamento de Imagens. Iniciação em Sensoriamento Remoto. $3^{\circ}$ ed.; São Paulo, Ofina de Textos, 2011. p. 71-78.

Cabral, N.R.A.J. \& Souza, M.P. Áreas de proteção ambiental: planejamento e gestão de paisagens protegidas,. 2 ed. São Carlos: RIMA, 2005. 158p.

MARCELINO, E. V. Ministério da Ciência e Tecnologia, INSTITUDO NACIONAL DE PESQUISAS ESPACIAS. Desastres Naturais e Geotecnologias: Conceitos Básicos. INPE, Santa Maria, 2007. Disponível em: < www.inpe.br/crs/geodesastres/conteudo/ publicações/conceitosbasicos.pdf >. Acesso em: 03 de Dezembro de 2006.

PREFEITURA MUNICIPAL DE CAMPO GRANDE. Plano de Manejo da Área de Proteção Ambiental dos Mananciais do Córrego Guariroba - APA do Guariroba. Secretaria Municipal do Meio Ambiente e Desenvolvimento Urbano - SAMADUR, volume1, 2008. Disponível em: <http://www.capital.ms.gov.br/semadur/canaisTexto?id_can=3148>. Acessado em 05/12/2013.

FITZ, P. R. Geoprocessamento sem complicação. Oficina de Textos. São Paulo, 2010.

LEPSCH, I. F. Formação e conservação dos solos. Oficina de textos. São Paulo, 2010.

BERTONI, J.; NETO, F, L. Conservação do solo. 3 ed. São Paulo. Ícone, 1990.

MAFRA, N. M. C. Erosão e Planificação de Uso do Solo. In: GUERRA, A. J. T.; SILVA, A. S.; BOTELHO, R. G. N. (Orgs). Erosão e Conservação dos Solos: Conceitos, Temas e Aplicações. $2^{\circ}$ ed. Rio de Janeiro: Bertrand Brasil, 2005. 340p.

CUNHA, K. L. Uso de Imagens LANDSAT e CBERS no Mapeamento da Suscetibilidade à Erosão na Região de Primavera do Leste - MT. Cuiabá, MT, 2009. Instituto de Física.

SMIDERLEL, O. J.; JUNIORLL, M. M.; SOUSALL, R. C. P. Tratamentos Pré-Germinativos em Sementes de Acácia. Rev. Bras. Sementes vol.27 no.1 Pelotas June 2005. 